Article

\title{
Spatiotemporal Polyrhythm Characteristics of Public Bicycle Mobility in Urban Chronotopes Context
}

\author{
Lijun Chen ${ }^{1, *(1)}$ and Shangjing Jiang ${ }^{2}$ \\ 1 School of Rail Transportation, Soochow University, Suzhou 215006, China \\ 2 School of Geographic Science, Nanjing Normal University, Nanjing 210023, China; 181302072@njnu.edu.cn \\ * Correspondence: ljchen@suda.edu.cn
}

check for updates

Citation: Chen, L.; Jiang, S. Spatiotemporal Polyrhythm Characteristics of Public Bicycle Mobility in Urban Chronotopes Context. ISPRS Int. J. Geo-Inf. 2022, 11, 6. https://doi.org/10.3390/ ijgi11010006

Academic Editor: Wolfgang Kainz

Received: 13 November 2021

Accepted: 26 December 2021

Published: 28 December 2021

Publisher's Note: MDPI stays neutral with regard to jurisdictional claims in published maps and institutional affiliations.

Copyright: (C) 2021 by the authors. Licensee MDPI, Basel, Switzerland. This article is an open access article distributed under the terms and conditions of the Creative Commons Attribution (CC BY) license (https:// creativecommons.org/licenses/by/ $4.0 /)$.

\begin{abstract}
Cycling rhythm performance is the result of a complex interplay between active travel demand and cycling network supply. Most studies focused on bicycle flow, but little attention has been paid to cycling rhythm changes for public bicycles. Full sample data of origin-destination enables an efficient description of network-wide cycling mobility efficiency in urban public bicycle systems. In this paper, we show how the spatiotemporal characteristics of cycling speed reveal the performance of cycling rhythms. The inference method of riding speed estimation is proposed with an unknown cycling path. The significant inconsistency of docking stations in cycling rhythm was unraveled by the source-sink relationship comparison. The asymmetry of the cycling rhythm on the path is manifested as the rhythm difference among paths and bidirectional inconsistency. We found that cycling rhythm has a temporal multilayer and spatial mismatch, which shows the inflection points of the cycling rhythm where the travel behavioral preference changes and the exact road segments with different rhythms. This finding suggests that a well-designed cycling environment and occupation-residential function should be considered in active transport demand management and urban planning to help induce active travel behavior decisions.
\end{abstract}

Keywords: rhythm analysis; public bicycle; speed; docking stations; cycling paths; spatiotemporal

\section{Introduction}

As a perfect combination of an active transport mode and sharing economy, the public bicycle has become an indispensable part of many urban residents' daily life [1]. It is widely used for commuting, shopping, leisure, and fitness by residents of all ages [2]. Observations of public bicycle travel showed that cycling speed varies in each cyclist and in different situations. The variability of the public bicycle speed within the urban space and certain time dimensions reflects the multiplicity of the rhythm of public bicycle mobility. This rhythm constitutes the interesting interleaving of riders, public bicycles, docking stations, urban chronotopes [3], and society. The latter two are the context and medium for public bicycle trips, respectively, which form new structural conditions and dynamic change through the interaction of public bicycle flow [4].

Previous studies have shown little focus on the analysis of cycling speed variability [5]. Although the speed of individual cyclists varies greatly, cyclist groups organize all kinds of elements in the form of repetition and correspondence to make up a coherent and orderly whole. The rhythm of public bicycle mobility is considered an integration of disordered different patterns of public bicycle flow, including regularity and heterogeneity on the spatiotemporal scope. It has been widely recognized that public bicycle flow is one of the remarkable means of analyzing public bicycle travel behavior, which can be considered as a special case of rhythm and a specific perspective of rhythm analysis. Public bicycle flow refers to the way in which social time and urban place semantic acts on residents' public bicycle trips. This type of rhythm can be explicit or invisible, as well as a kind of special repetition or a stretch of time differentiation in space. However, previous studies have 
not given a clear conclusion. Cycling speed provides an important platform to identify the rhythm. Distinguishing and comparing the polyrhythm of public bicycle mobility is conducive to understanding the riding efficiency and corresponding reasons in different contexts, which provide references for improving the riding environment, planning special bicycle lanes, and improving the comfort and safety of public bicycles.

The randomness of bicycle trips, the discontinuity of scenario capture, and the acquisition difficulty of cycling speed data may be possible reasons for the less attention paid to cycling speed variability, whereas traffic flow theory focuses on readily available pedestrians and automobiles [6-8]. In previous limited studies, cycling speed is obtained using stopwatch, radar, video, and global positioning system instruments [9], which cannot solve the homogenous nature of data. Through the public bicycle operation system, a massive amount of data recording the activities of all public bicycle users can be obtained, which offers a good opportunity to analyze the rhythm of public bicycle mobility. It provides a perspective of spatiotemporal correlation between public bicycle travel behavior and public bicycle flow by applying traffic flow theory in the public bicycle system.

This paper aimed to explore the polyrhythm of public bicycle mobility based on cycling speed from the perspective of urban chronotopes and investigate the main reasons of how the temporal stratification and spatial heterogeneity of cycling polyrhythm occur. The contribution of this study is twofold. First, the detailed paths of public bicycle trips could be determined with high probability by using smart matching of map route estimation and comparison. Previous studies paid more attention to the site OD (origin-destination) of dockless or docked bike sharing systems, but rarely analyzed the exact path of public bicycles. This study aims to fill the research gap. Second, different degrees of time fluctuation rules and very obvious spatial distribution characteristics are found in public bicycle trip rhythm research. To support this, the observation scope of public bicycle mobility rhythm covers the full sample data of all citizens in this study rather than a small or specific group of respondents in previous bicycle speed research. To some extent, the rhythm of public bicycle trips also reflects the life rhythm of cities, thereby potentially providing policy implications for future transport policy design. The remainder of the paper is organized as follows: Section 2 provides a brief summary of earlier literature, Section 3 describes the study object and detailed methodology, Section 4 presents the analysis results, Section 5 discusses some related issues, and Section 6 summarizes the conclusions.

\section{Literature Review}

\subsection{Rhythms and Its Relevant Analysis}

The concept of rhythm is used to describe the speed and intensity in music or poem. It also refers to an etiquette system or a regular process [10]. Lefebvre claimed that rhythm is an experienced subjective interaction among place, time, and expenditure of energy [11]. Furthermore, a rhythm analysis method was proposed to emphasize the categories of change and repletion, identity and difference, and contrast and continuity [12]. In addition, application demand can be used to explore the relationship among planned events, urban spatiality, and authentic place experience [13]. Rhythmical nature is emphasized by the existential modality of the interrelationships of individual, city, and event rhythms [14].

There is a wide range of theoretical methods of rhythm analysis with respect to different kinds of applications, such as ethnography with photo or video data, psychogeography with a situation approach, and phenomenology [15]. Rhythm analysis has also been applied in a range of fields, including the daily life and daily travel of citizens or rural residents [16,17], urban retail landscapes for shopping [18], tourism, and air pollution [19]. For instance, human daily circadian rhythms were explored for native Brazilians who are living without electricity in summer and winter [20]. Rural rhythm was found to be vague and diffuse by analyzing the local ways of habitation. Significant potential was demonstrated by investigating the rhythms of the hosts and visitors of Telemark Canal in Norway [21]. Moreover, the specific features of practicing sleep in nature holidays were analyzed from the perspective of rhythms by ethnography [22]. 
Studies regarding rhythm analysis in the transportation field are relatively limited. A macroscopic fundamental diagram was used to describe the efficiency of networkwide performance to disentangle city traffic rhythms [23]. Location data are becoming popular in rhythm analysis [24]. For instance, the diurnal rhythms of suburban commuters' movements in Tallinn were analyzed based on mobile telephone positioning data [25], and the geographical patterns of a city's diurnal rhythm were distinguished from the aggregate data of social media in over 340 Chinese cities [26]. Recent research has aimed to describe daily urban rhythms in terms of human mobility. A microscope with a gas injection system was constructed based on person-trip data to reveal the regional features and differences of dynamic mobility behavior [27]. In summary, rhythm analysis is helpful to grasp the multidimensional dynamic pattern of human behavior.

\subsection{Travel Behavior of Shared Bicycle}

A bundle of literature has focused on bike-sharing systems, which has laid the foundation for the rhythm analysis of shared bicycles. From the perspective of social humanistic attributes, gender, age, income, household size, commute type and length, and vehicle ownership play important roles in bike sharing usage [28]. For example, bike sharing, as a stand-alone system or in conjunction with public transport, is less suited to be used by women and older age groups in Oslo, Norway [29]. Low-income populations, people of color, and transit-dependent households are not highly representative of the riders' profile [30]. Members who reside in minority-concentrated neighborhoods with low socioeconomic status use shared bicycles more frequently [31].

The reasons for choosing shared bicycle travelling have been widely explored. The most influential factors for shared bicycle use include the strategic location of docking stations, the ease of signing up, and integration with public transport [32]. Moreover, built environment attributes, such as the bike index, land use diversity index, transit accessibility, density of destinations, and length of bike infrastructure, might also influence the choice of shared bicycle [33]. In addition, bicycle components (e.g., the frame, saddle, handlebar), environmental factors (e.g., road type, weather), and cyclist status (e.g., adjustments, body parts) would affect the comfort of shared bicycle use [34]. In general, social humanistic attributes, environment attributes, and bike sharing system attributes are likely to be considered influence factors for cycling travel behavior, which provide the basis for cause analysis of the characteristics of cycling rhythm.

\subsection{Cyclist Speeds}

Research on bicycle speed is relatively limited and focuses on the relationship between cycling safety and cycling speed [35]. The relationship between helmet use and cycling speed under naturalistic conditions was explored based on risk compensation; the results showed that gender plays a remarkable role in cycling speed rather than helmet use [36,37]. On shared paths, higher cycling speeds may be realized through the visual segregation of different materials or paint color from pedestrians without a substantial loss of safety [38]. A support vector machine was adopted to categorize cycling environments in terms of safety and comfort. The cycling speeds of e-bikes (pedelec, S-pedelec) and conventional bikes were compared; the results showed that electric bicycles indeed reach higher speeds than conventional bikes with a high risk of a crash [39]. E-bikes could reduce perceived cycling effort by reaching higher speeds compared to conventional bicycles but increase users' misjudgments for predefined positions [40]. A few accepted gaps in front of approaching bicycles were tested to be especially risky based on the effects of bicycle speed and bicycle type [41].

Studies on bicycle travel behavior assume that cycling speed is a fixed threshold value or average value by default instead of a variable riding speed [42]. The earliest tool used to obtain the average speed of cyclists was a stopwatch, and the average speed tends to lie between 12 and $20 \mathrm{~km} / \mathrm{h}$. Subsequently, radar measurement devices were applied; however, these devices still have some shortcomings, such as missing or wrong data. The 
use of video data from a camera can more accurately examine a cyclist's acceleration speed, deceleration, and headway. Nonetheless, the result is affected by the installation location of cameras, and the cycling speed scene cannot be completely captured. A global positioning system (GPS) device is designed to be carried by cyclists or installed on a bicycle handle, or a smartphone with GPS is applied, to record selected bicycle users [43]. The pertinence of selected data acquisition objects has been strengthened by this method, but the full nature of data for all bicycle users still cannot be obtained. At present, the big data of shared bicycle operation provide detailed information of the time, space, and flow for all bicycle users, which provides a great advantage. Only one relative study refers to bike sharing; this study measured the speed of shared bicycles in Lyon and found that cyclists' average speed reaches a peak of $14.5 \mathrm{~km} / \mathrm{h}$, which may be seen as an intrinsic limit of the system [44]. The importance of research on the speed of public bicycles is mentioned but limited detailed research has been conducted.

\section{Methods}

\subsection{Study Area and Data Description}

This study case is conducted on the public bicycle sharing system of Suzhou, China, which is adjacent to Shanghai with a population of 10.75 million. Suzhou is one of the most highly developed cities in east China. The study area is located at the city's center, including districts of Gusu, Huqiu, Wuzhong, and Xiangcheng (Figure 1). This study collected 132,106 records of trip data under the docked public bicycle scheme on 28 May 2018 in Suzhou. The date was a Monday with the nature of being a workday with favorable weather conditions. Each data record contains the number of trips, the names and locations of docking stations where the bicycles were borrowed and returned, and the time the bicycles were borrowed and returned. The latitude and longitude coordinates of each docking station are also obtained.

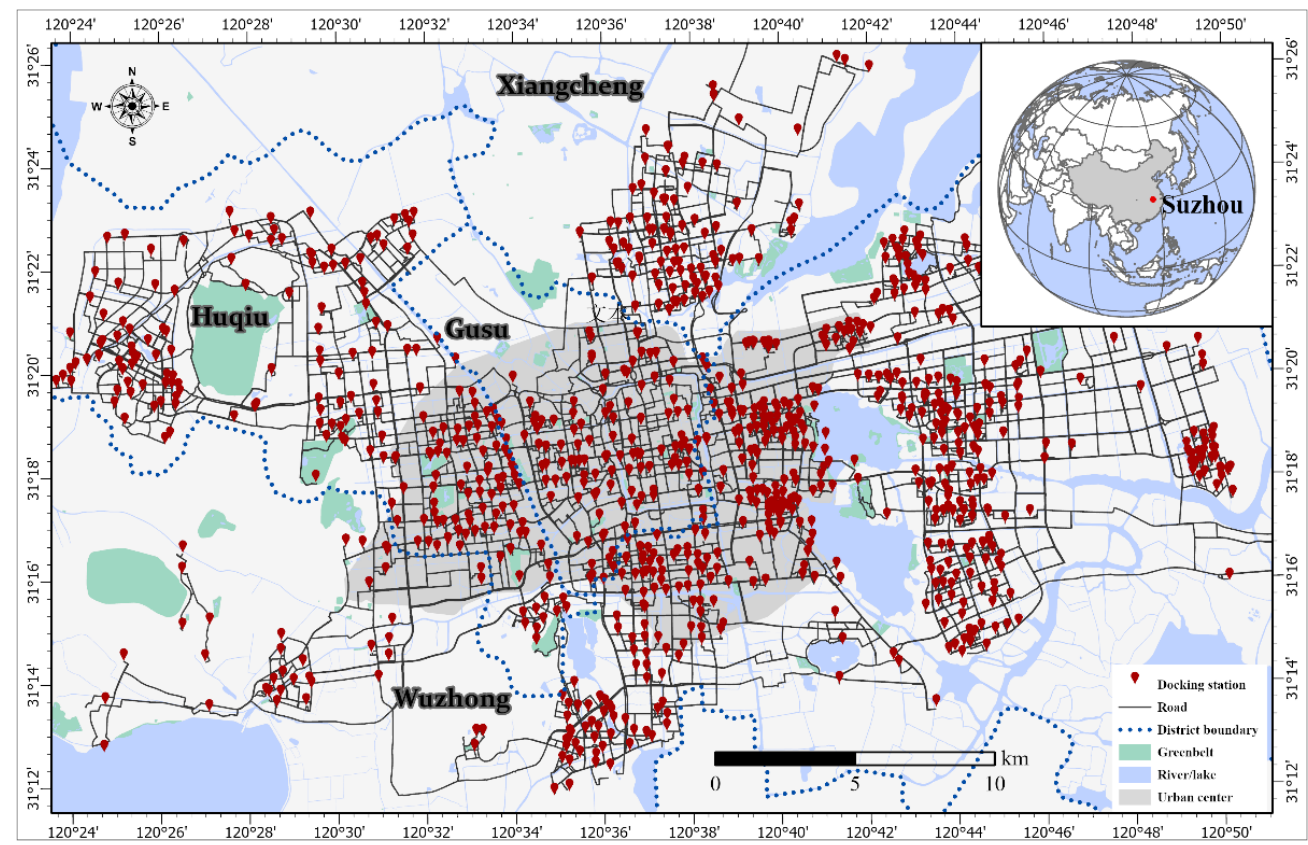

Figure 1. Study area (public bicycle system in Suzhou, China).

\subsection{Cycling Speed Calculation Model from Origin Station to Destination Station}

The data used in this study are the operational data of a docked public bicycle system. The data field types include the lending position, lending time, returning position, and returning time. That is, only origin-destination (OD) information of cycling trips could be gained from the database. As known, the docked public bicycles in Suzhou are not equipped with GPS instruments as the dockless shared bicycles. Therefore, the detailed 
paths of every cyclist cannot be obtained automatically without a sampling interval. This means that the time spent on a ride can be captured, but the exact path, as well as the corresponding cycling distance and speed, is difficult to measure directly. Therefore, a feasible strategy used in this paper was to determine the relatively accurate path of public bicycle trips with the help of an online traffic path planning and analysis map. The implementation principle of this strategy is shown in Figure 2.

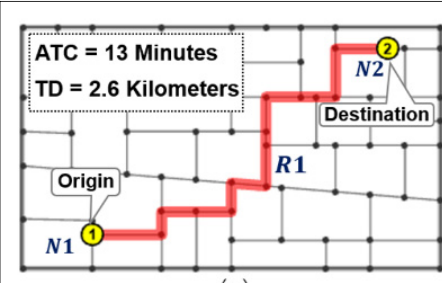

(a)

\begin{tabular}{|l|l|l|l|}
\hline RID & Origin & Destination & Time \\
\hline u1 & N1 & N2 & 14.2 \\
\hline u2 & N1 & N2 & 13.4 \\
\hline u3 & N1 & N2 & 14.3 \\
\hline u4 & N1 & N2 & 13.3 \\
\hline u5 & N1 & N2 & 15.6 \\
\hline$\ldots$ & $\ldots$ & $\ldots$ & $\ldots$ \\
\hline
\end{tabular}

(d)

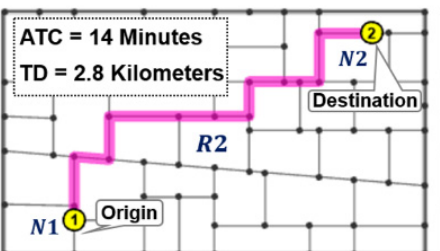

(b)

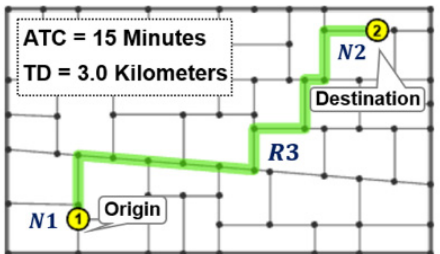

(c)

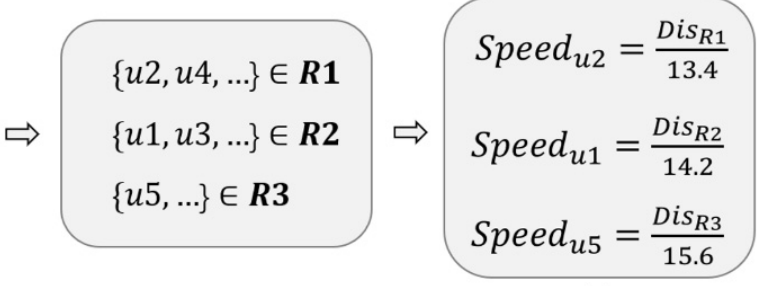

(e)

(f)

ATC: Average time cost; TD: Total distance.

Figure 2. Online map-based riding path inference method. (a) Scheme I; (b) Scheme II; and (c) Scheme III of path planning; (d) riding records of origin, destination, and cost time; (e) matching result of riding record and path; (f) speed calculation of each riding record.

In this study, the accuracy of cycling path estimation could be greatly improved by the choice of an online map with good quality, strict screening outliers, and small sample verification of personal experience by researchers. Assuming the lending station N1 and the returning station $\mathrm{N} 2$ for any public bicycle trip record, multiple paths may lead from $N 1$ to N2. The main difference between these multiple paths is the cycling length and time. Most online electronic maps aid in path planning, which provides a clever and practical method for the contrast test. This study applies AMAP, which is one of the most widely used online maps in China to extract the above information. AMAP is a leading digital map content navigation and location service solution provider in China. It has mapping qualifications for a navigation electronic map and Internet map service with a high-quality electronic map database. Thus, the origin and destination of public bicycle docking stations are also provided by AMAP by choosing cycling as the travel mode. Some cycling path solutions are then recommended and provide information regarding the corresponding length and time of each path.

As shown in Figure 2a-c, N1 to N2 has three recommended paths, namely $R 1, R 2$, and R3. Obviously, although the origin and destination points of the three paths are the same, the three paths have different lengths and times taken. The lengths of $R 1, R 2$, and $R 3$ are 2.6, 2.8 , and $3.0 \mathrm{~km}$, respectively, and take 13,14 , and $15 \mathrm{~min}$ to travel, respectively. Figure $2 \mathrm{~d}$ shows the lending and returning data of public bicycles obtained from the Suzhou Public Bike System, from which the number of trips between $N 1$ and $N 2$ are many $(u 1, u 2, u 3, u 4$, $u 5$, etc.). The timestamp duration of each public bicycle trip can be calculated by subtracting the returning time and lending time in the operational database. The actual time taken by $u 1-u 5$ was $15.2,13.5,16.4,13.3$, and $18.6 \mathrm{~min}$, respectively. A comparison of the actual time taken and the recommended time taken for each record revealed that the closer the two values are, the more the path matches. Here, the path from N1 to N2 and its length were determined, and the average travel speed of each public bicycle trip was calculated. 
For example, the public bicycle trip $u 1$ takes $14.2 \mathrm{~min}$, which is the nearest to the time taken of $R 2$ as shown in Figure $2 \mathrm{~b}$ (14 min). Therefore, the path of $u 1$ matches $R 2$. Thus, the length of $u 1$ is $2.8 \mathrm{~km}$, and the actual time taken is $14.2 \mathrm{~min}$. Thus, the average speed of $u 1$ can be calculated as the division of two numbers, which is equal to $11.81 \mathrm{~km} / \mathrm{h}$. Similarly, the speed of each public bicycle trip record can be calculated. Any special trip records with an actual time taken that is far less than or much longer than the recommended time in the online map planning path were not included in the calculation of this study to reduce the error caused by individual uncertainty. In this study, around $1.5 \%$ of the total records, of which the speed outliers are below $5 \mathrm{~km} / \mathrm{h}$ and above $30 \mathrm{~km} / \mathrm{h}$, have been excluded.

\subsection{Polyrhythm Analysis Methods for Public Bicycle Mobility}

Rhythm refers to the regular or irregular periodic changes in multidimensional space, including height, width, depth, and time. All rhythms have a certain speed, and the combination of different rhythms forms the rhythm mode with a certain performance. Therefore, speed is considered as the main factor to understand the polyrhythm characteristics of public bicycle trips in different places, paths, and regions in this paper. Here, speed refers to the average speed of each public bicycle trip.

\subsubsection{Cycling Rhythm Calculation Based on Docking Station}

Each public bicycle trip datum corresponds to an origin-destination (OD) cycling flow. We define the origin docking station as a "source" and the destination docking station as a "sink". The source rhythm was obtained by calculating the average speed of all OD flows departing from a station. Similarly, the sink rhythm was obtained by calculating the average speed of all OD flows arriving at a station.

Figure 3a shows the spatial distribution diagram of all public bike docking stations in a certain area. Figure $3 b-f$ describes the statistical analysis principle of source and sink rhythms based on stations. First, a specific docking station was selected as the target site and labeled $p_{0}$. Then, all the OD flows that departed from $p_{0}$ were extracted, and the riding distances that exceeded a certain threshold radius $(3 \mathrm{~km})$ were excluded as shown in Figure $3 \mathrm{~b}, \mathrm{e}$, which was generated from Figure $3 \mathrm{a}$. Herein, $p_{i}$ represents the target source docking station. The source rhythm value $\left(\bar{V}_{i \_ \text {in }}\right)$ was calculated as follows:

$$
\bar{V}_{i \_ \text {in }}=\frac{1}{n_{i}} \sum_{i=1}^{n_{i}}\left(\frac{\sum_{j=1}^{n_{i j}} \frac{l_{i j}}{t_{i j}}}{n_{i j}}\right)
$$

where $n_{i}$ represents the number of the docking stations within a given threshold departing from $p_{i} ; n_{i j}$ represents the number of OD flows from $p_{i}$ to $p_{j}$; and $l_{i j}$ and $t_{i j}$ represents the actual length and time taken from $p_{i}$ to $p_{j}$, respectively.

Similarly, $\bar{V}_{i \_o u t}$ represents the corresponding sink rhythm value, which was calculated as follows:

$$
\bar{V}_{i \_ \text {out }}=\frac{1}{m_{i}} \sum_{i=1}^{m_{i}}\left(\frac{\sum_{j=1}^{m_{j i}} \frac{l_{j i}}{t_{j i}}}{m_{j i}}\right)
$$

where $m_{i}$ represents the number of docking stations within a given threshold arriving at $p_{i}$, and $m_{j i}$ represents the number of OD flows from $p_{j}$ to $p_{i}$.

Notably, the number and paths of trips from $p_{i}$ to $p_{j}$ and from $p_{j}$ to $p_{i}$ are different in practice. Figure $3 c, f$ shows the calculation results of the source and sink rhythms of the docking stations, which were generated from Figure $3 \mathrm{~b}$,e respectively. The rhythm value varies from station to station. In addition, the composition distribution of the speed may be different for the same average speed value. Inconsistency in the cycling rhythm of OD can be classified by the clustering method in Figure 3d, which was generated from the combination of Figure $3 \mathrm{c}$,f. Finally, the contour lines of cycling rhythms obtained by the spatial interpolation method were used to describe the equivalent distribution of 
cycling rhythms in different urban areas intuitively as shown in Figure $3 \mathrm{~g}$, which was also generated from the combination of Figure $3 c, f$.

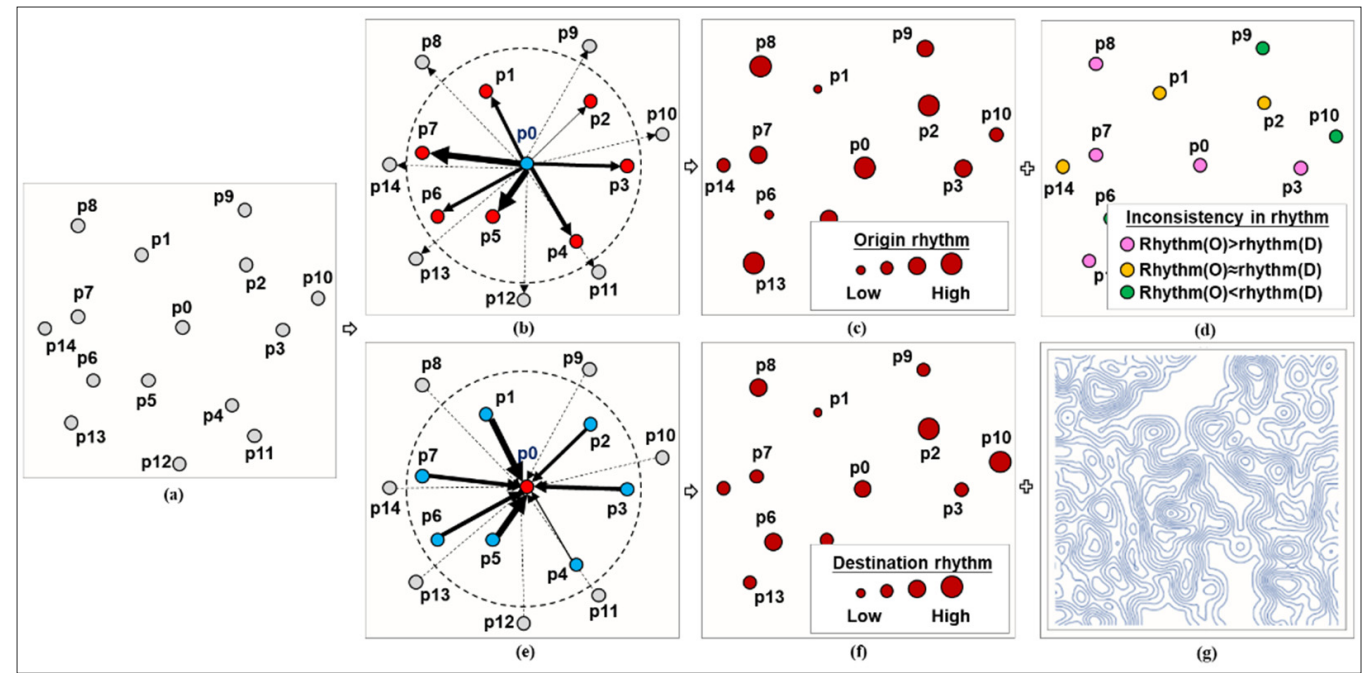

Figure 3. Rhythm analysis flow chart based on the docking stations of public bicycles. (a) spatial distribution of all public bicycle docking stations; (b) source stations; (c) origin rhythms; (d) inconsistency in rhythm; (e) sink stations; (f) destination rhythms; (g) rhythm contour.

\subsubsection{Cycling Rhythm Calculation Based on Path Segment}

Cycling rhythm is also reflected based on paths. It can help to provide a better understanding of the magnitude of the rhythm value and rhythm patterns for each segment. Each path is composed of several segments from the origin to the destination. The speed of each segment is determined by all the public bicycle trips that passed the segment. For example, suppose that we have three paths $(a b, c d$, and $e f)$ for public bicycles travelling in a certain area over a period of time (Figure 4a); the number of public bicycle trip records on the three paths are $m, n$, and $k$, respectively, and the speeds of the paths are expressed as $V_{a, b_{-} i}, V_{c, d_{-} i}$, and $V_{e, f_{-} i}$, respectively. The three paths are superimposed in Figure $4 \mathrm{~b}$. The set of road nodes for path $a b\left(R_{a b}\right)$ is $(7,8,9,12,13,20,25,30,34)$. Every two consecutive nodes represent a road segment; thus, $R_{a b}$ has eight segments. Figure $4 \mathrm{~d}$ shows the segment node set of $R_{a b}, R_{c d}$, and $R_{e f}$.

The total number of public bicycle trips passed on each segment can be marked by different colors (Figure $4 c$ ). $L_{12,13}$ is the path segment bounded by the road nodes 12 and 13 . Similarly, $L_{13,12}$ is the path segment bounded by the road nodes 13 and 12 (the numbers in subscript represent road nodes, and the sequence of numbers represents the path segment direction). For example, $L_{13,12}$ passed by paths $c d$ and $e f$, whereas $L_{12,13}$ only passed by path $a b$, and $L_{29,33}$ only passed by path ef. The corresponding formulas are as follows:

$$
\begin{gathered}
V_{13,12}=\frac{1}{2}\left(\frac{1}{n} \sum_{i=1}^{n} \mathrm{~V}_{c, d_{-} i}+\frac{1}{k} \sum_{i=1}^{k} \mathrm{~V}_{e, f_{-} i}\right) \\
V_{12,13}=\frac{1}{m} \sum_{i=1}^{m} V_{a, b_{-} i} \\
V_{29,33}=\frac{1}{k} \sum_{i=1}^{k} V_{e, f_{-} i}
\end{gathered}
$$

The rhythm flow chart of the public bicycle path on the road section can be completed based on all the speeds of paths calculated. The OD flows between every two docking stations are different and need to be calculated separately. Figure 4e shows the high- to low-speed distribution among stations, whereas Figure $4 \mathrm{f}$ shows the reverse. 


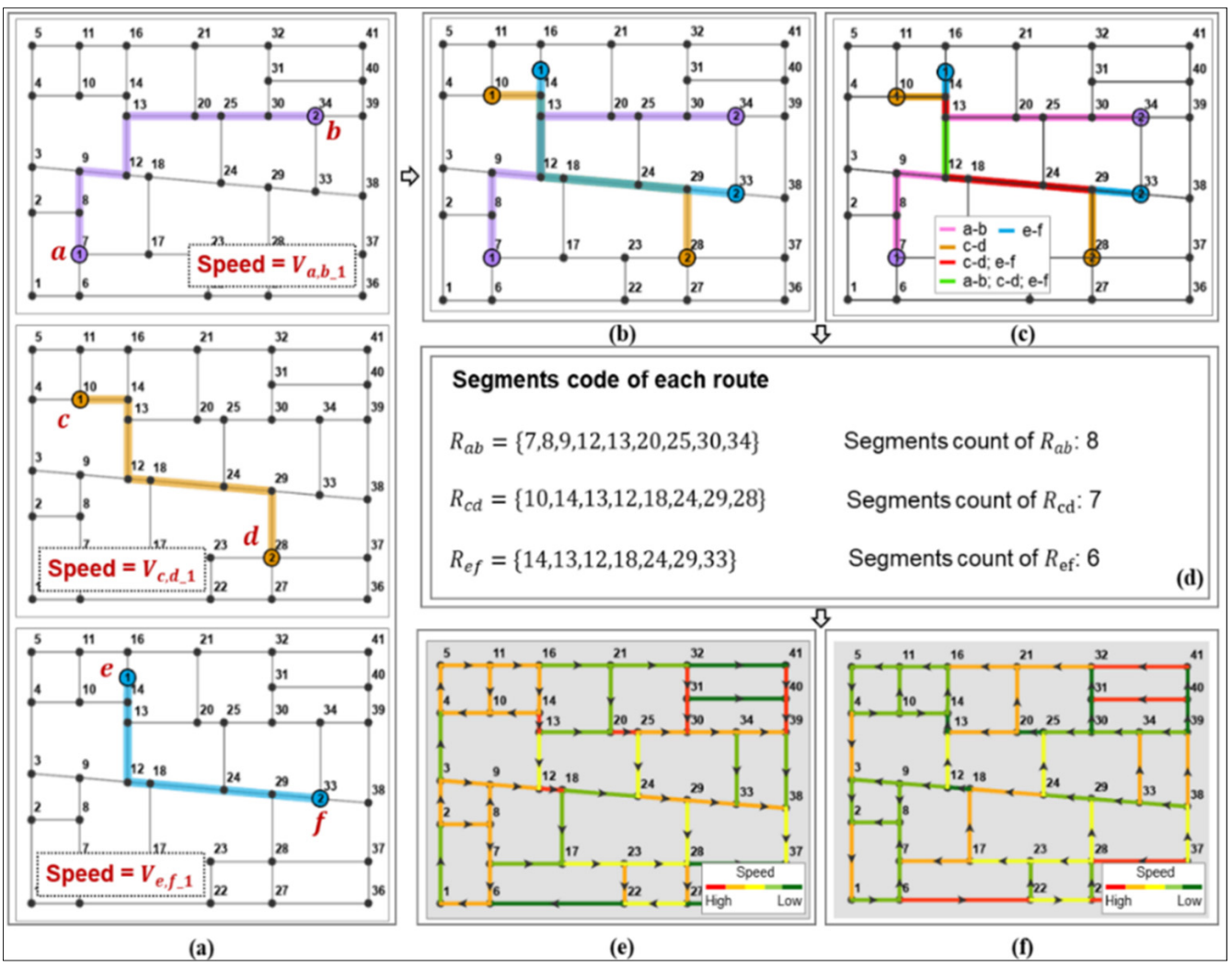

Figure 4. Rhythm analysis method based on the cycling paths of public bicycles. (a) three cycling paths of public bicycles trips; (b) the overlap of three cycling paths on roads; (c) decomposition of cycling paths on road segments; (d) segments code of each route; (e) the high- to low-speed distribution of cycling on road segments; (f) the low- to high-speed distribution of cycling on road segments.

\subsubsection{Spatiotemporal Rhythm Analysis Model}

The spatiotemporal cubic pattern analysis method and time series clustering model were used to investigate the distribution of cycling rhythm throughout the day within urban area limits [45-47]. First, the study area was divided into a grid of $500 \mathrm{~m}$ in size, in which each cube was constructed based on this grid with the same length and width at a time interval of $30 \mathrm{~min}$. Then, the average rhythm value in each unit of space-time cube was aggregated statistically as an attribute parameter for visualization. Finally, the pattern of each cube was identified by the spatiotemporal hot spot detection method. Here, hot mode means that the high value of cycling rhythm in this spatial range and time period is higher than the surrounding area at the level of statistical significance. On the contrary, cold mode means that the cycling rhythm in this spatial range is lower than the surrounding value during this period. In addition, random distribution means that its rhythm value is higher or lower than the surrounding space-time cube in the space range and time period. The time series clustering model can identify all spatial units with the most similar change characteristics in rhythm in the space-time cube and divide these spatial units into the same pattern category. Therefore, the spatial distribution map of pattern categories and the spatiotemporal variation curve of each pattern can be combined to analyze the spatial structure characteristics of cycling rhythm patterns and the temporal variation characteristics of each pattern.

\section{Results}

\subsection{Descriptive Statistics of Cycling Rhythm Volatility}

The results come from membership data for cyclists rather than management data for bicycle relocation. The speed of the overall volatility of the observed cycling rhythms and 
the trip count in speed stratification were characterized at 30-s intervals within a day as shown in Figure 5. Among the 27 rhythm gradients in Figure 5a, the maximum value is $29.9 \mathrm{~km} / \mathrm{h}$ and the minimum value is $5 \mathrm{~km} / \mathrm{h}$. The average speed is $12.7 \mathrm{~km} / \mathrm{h}$ and the median value is $12.2 \mathrm{~km} / \mathrm{h}$. The skewness value of the curve is 0.9 , which indicates that the probability distribution of the normal vector distance is skewed to the right. The kurtosis value of the curve is 4.4 , which means the cycling rhythm distribution is higher than the normal distribution. The majority of the cycling trips tend to be between 9 and $16 \mathrm{~km} / \mathrm{h}$ with an $85 \%$ point line of $14.3 \mathrm{~km} / \mathrm{h}$ and a $15 \%$ point line of $9.6 \mathrm{~km} / \mathrm{h}$. The maximum speed of public bicycles is around $25 \mathrm{~km} / \mathrm{h}$. We also found that those over $25 \mathrm{~km} / \mathrm{h}$ account for $1.3 \%$, which might be caused by sliding down the slopes in cycling activities.

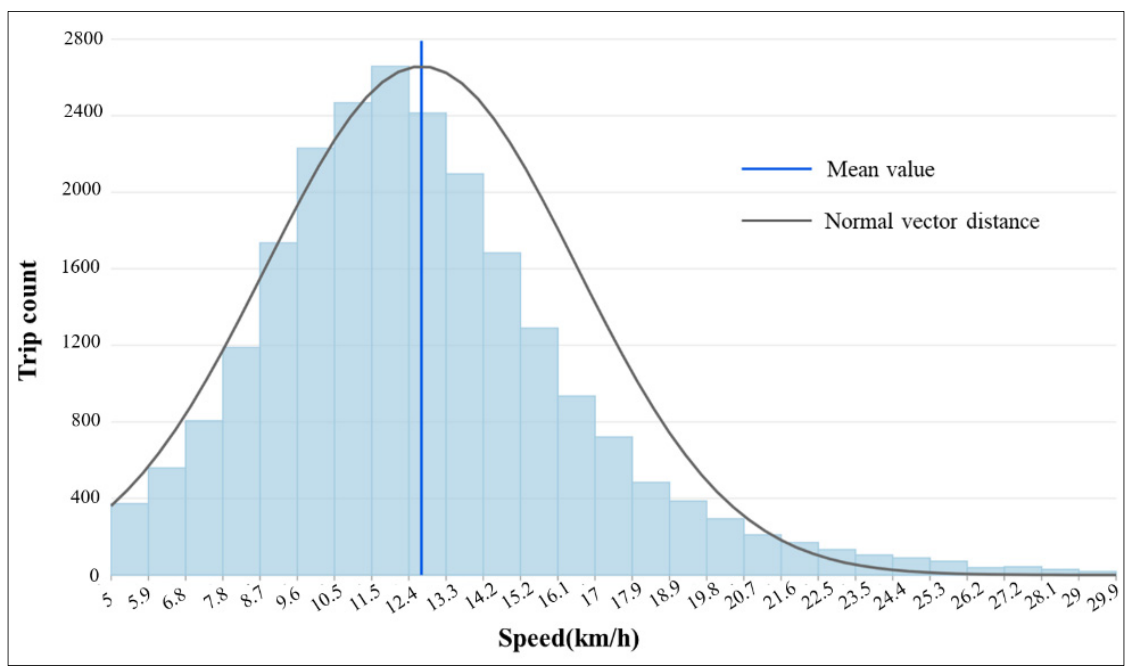

(a)

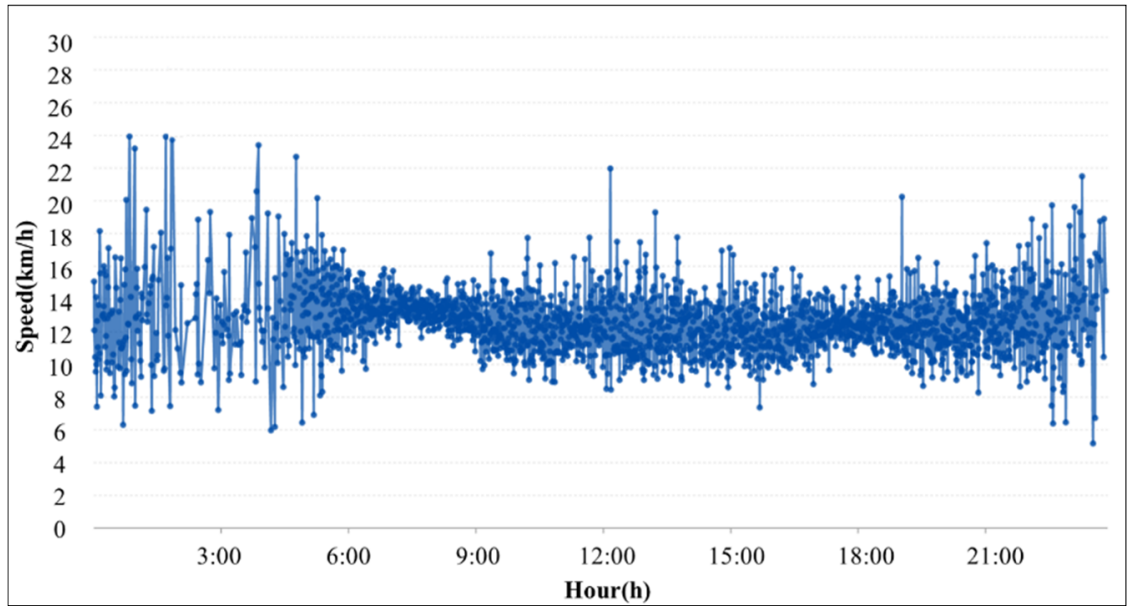

(b)

Figure 5. Descriptive statistics of cycling rhythms volatility. (a) volatility of trip count variation; (b) volatility of time variation.

Figure $5 \mathrm{~b}$ indicates that the rhythm tapping of cycling is sparse and higher at night, whereas rhythm tapping is much more intense and relatively lower in the daytime. The whole curve of cycling rhythm changes in the shape of a twisted rope. The time duration of high-rhythm cycling rides is about $4 \mathrm{~h}$, which suggests that an empty riding environment and fewer conflicts from pedestrians/vehicles would greatly improve the cycling rhythm. Moreover, cyclists' eagerness to get home at night also forces the pace. With the increase in the traffic flow during the morning peak, the cycling rhythm shows a remarkable decrease and a high concentration between 12 and $14 \mathrm{~km} / \mathrm{h}$. Similar changes occur during the 
evening peak, but the amplitude is smaller and the duration is shorter. The cycling rhythm is relatively steady between 8 and $18 \mathrm{~km} / \mathrm{h}$ with the individual high rhythm larger than $20 \mathrm{~km} / \mathrm{h}$ from 9 a.m. to 4 p.m. Additionally, the cycling rhythm before 10 p.m. is similar to that in the afternoon and begins to rise again after $10 \mathrm{p} . \mathrm{m}$. The performance of the night cycling rhythm strongly suggests that public bicycles are considered a very active vehicle for night travel.

\subsection{Cycling Rhythms Based on Source-Sink Comparison}

As the direct carrier of the source-sink relationship, public bicycle docking stations are the focus of cycling rhythm. Cycling rhythms were calculated from each docking station. The results are shown in Figure 6a,b. On this basis, the characteristics of rhythmic inconsistency and its spatial distribution were statistically analyzed (Figure 6c). Then, the cycling rhythm contour was visualized to understand the overall cycling rhythm in the urban setting (Figure 6d).

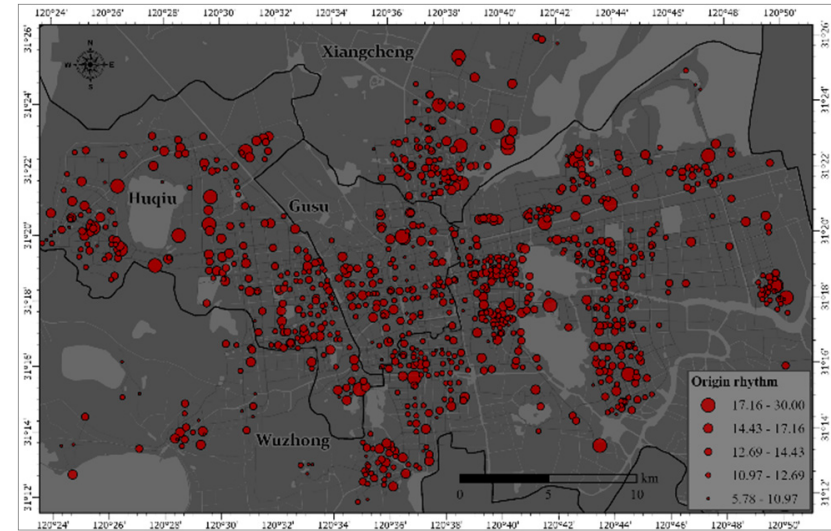

(a)

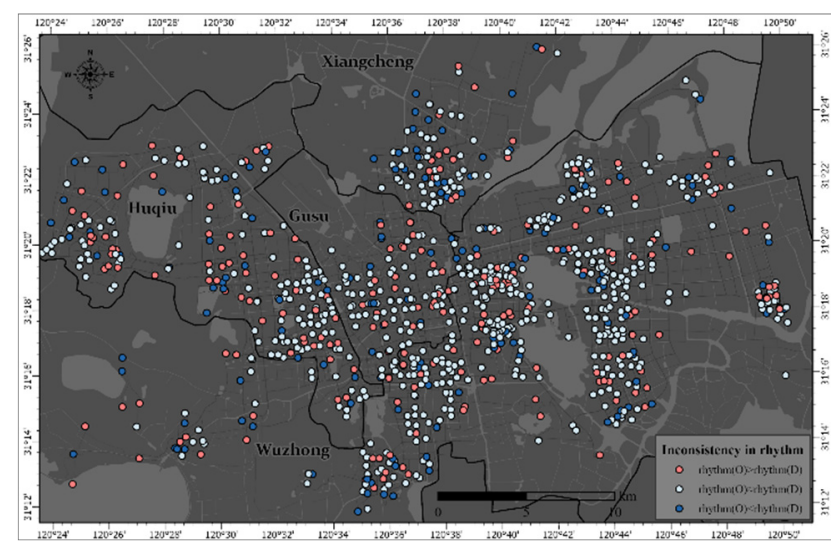

(c)

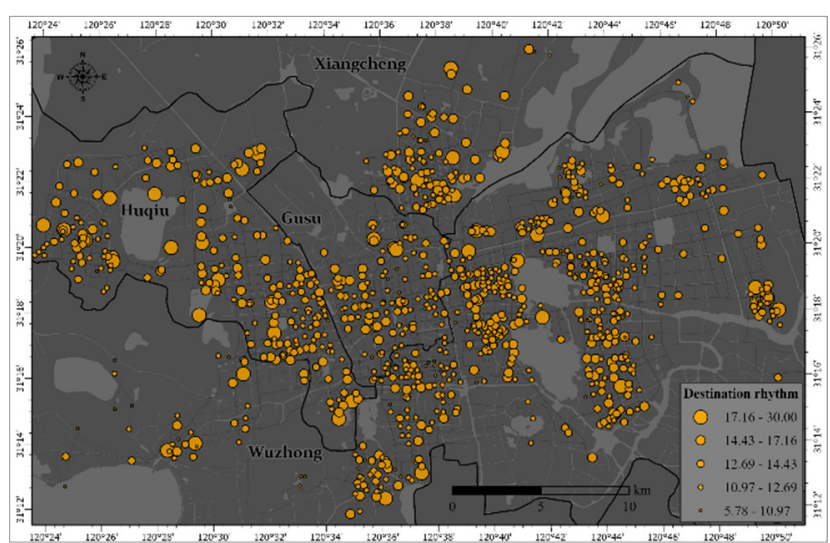

(b)

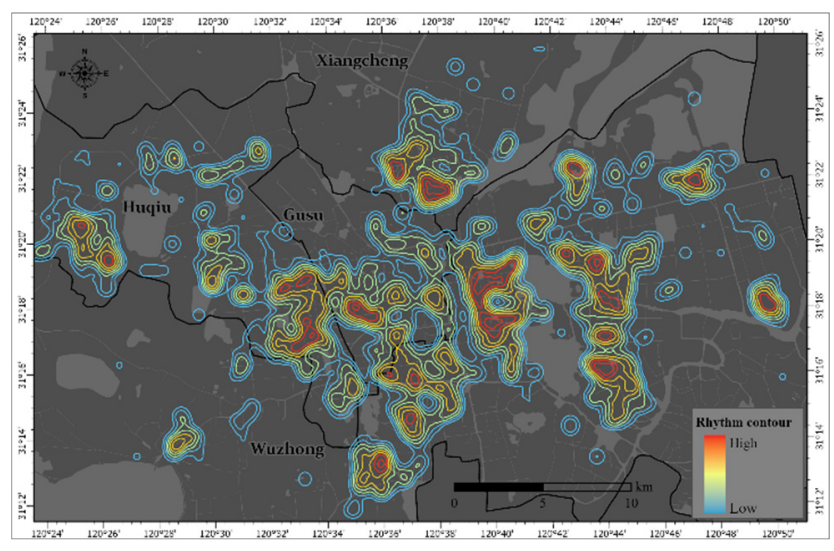

(d)

Figure 6. Distribution of cycling rhythm based on stations. (a) source rhythm of stations; (b) sink rhythm of stations; (c) inconsistency in cycling rhythm; (d) cycling rhythm contour.

Cycling rhythms with a focus on stations are divided into five groups as shown in Figure $6 \mathrm{a}, \mathrm{b}$. Group 1 with a speed value of $17.16-30 \mathrm{~km} / \mathrm{h}$ has the fastest rhythm, whereas group 5 with a speed value of $5.78-10.97 \mathrm{~km} / \mathrm{h}$ has the slowest rhythm. Groups 2, 3, and 4 had speed values of 14.43-17.16, 12.69-14.43, and 10.97-12.69 km/h, respectively, and were considered to have fast, medium, and slow rhythms, respectively. The statistics show that the ratios of the five groups of source rhythms from the origin stations are $4.3 \%, 17 \%, 33.5 \%$, $38.3 \%$, and $6.9 \%$ from the fastest rhythm to the slowest rhythm, respectively. Similarly, the ratios of the five groups of sink rhythms from destination stations are $4.6 \%, 17.8 \%, 30.4 \%$, 
$38.3 \%$, and $8.9 \%$ from the fastest rhythm to the slowest rhythm, respectively. It is observed that more than $80 \%$ of cyclists prefer the speed threshold from $11 \mathrm{~km} / \mathrm{h}$ to $17 \mathrm{~km} / \mathrm{h}$. This may be related to the design speed of the public bicycle, the purpose of travel, and the physical fitness of the cyclists. Source and sink rhythms seem to have little difference in terms of fine-grained quantity.

However, the spatial distributions of source and sink rhythms are quite different. The details of cycling rhythms at each station can be queried from the maps if needed. From the perspective of location characteristics, origin stations may have a high rhythm in residential areas surrounded by workspace and schools, and vice versa. As shown in the southeast and southwest sides of the city area in Figure $6 a, b$, the source and sink rhythms of such places are complementary to each other. It is found that by comparing each station's source and sink rhythms in Figure 6c that source and sink rhythms were approximately equal at $62.1 \%$ of stations, $22.9 \%$ of the stations' source rhythms were faster than sink rhythms, and $16 \%$ of the stations' source rhythms were slower than sink rhythms. Specifically, around 38.9\% of public bicycle docking stations show substantial inconsistency in cycling rhythm based on the source-sink relationship comparison. For example, the cycling rhythm from the resident community to schools may be faster than that from schools back to the resident community.

More obviously, the contour lines of cycling rhythms show that high-cycling-rhythm areas have a binuclear cluster type with the zonal distribution. The zonal feature is more noticeable on the east side and extends to the north and south sides. According to the spacing characteristics of isorhythmic lines, gradient changes in the acceleration and deceleration of cycling rhythms are relatively uniform in most areas.

\subsection{Cycling Rhythms Based on the Asymmetry of Paths}

As the intermediate carrier of public bicycle riding, roads also reflect the cycling rhythm. The average rhythmic distribution map of all paths in the study area obtained through online map-based riding path recognition and the cycling rhythm calculation of segments is shown in Figure 7a. According to the natural discontinuity method, cycling rhythms with a focus on paths are divided into five types. The details of the cycling rhythms of each segment can be queried from the maps.

Type 1 accounts for $31.60 \%$ of the total path length and has the highest rhythm with a speed value of $14.20-18.1 \mathrm{~km} / \mathrm{h}$. Type 2 accounts for $14.56 \%$ of the total path length and has a high rhythm with a speed value of $12.95-14.2 \mathrm{~km} / \mathrm{h}$. Type 3 accounts for $17.81 \%$ of the total path length and has a medium rhythm with a speed value of $11.56-12.95 \mathrm{~km} / \mathrm{h}$. Type 4 accounts for $23.04 \%$ of the total path length and has a medium rhythm with a speed value of $9.22-11.56 \mathrm{~km} / \mathrm{h}$. Lastly, type 5 accounts for $12.98 \%$ of the total path length and has a medium rhythm with a speed value of $5.80-9.22 \mathrm{~km} / \mathrm{h}$. The proportion of high rhythm in the east of the city is more than that in other regions, whereas the corresponding proportion in the north is the least. The high-rhythm paths on the west and east sides have a remarkable agglomeration distribution feature and maintain a high rhythm for a long section. In contrast, the distribution of high-rhythm paths in the central city and south side is discrete and fragmented. 


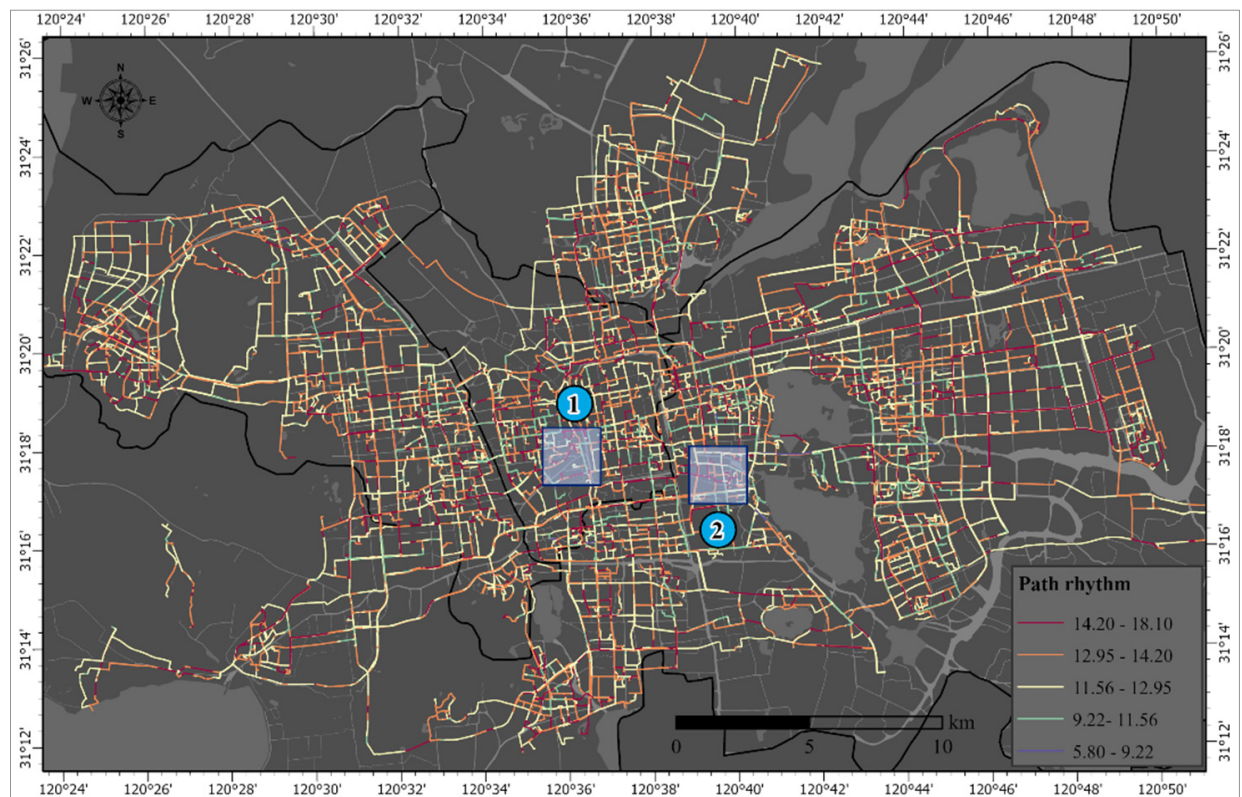

(a)

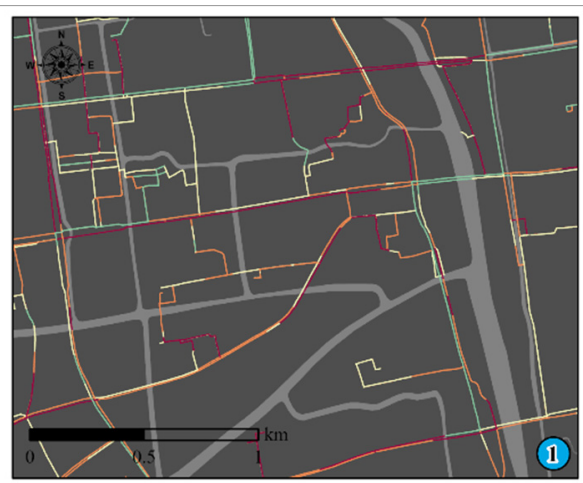

(b)

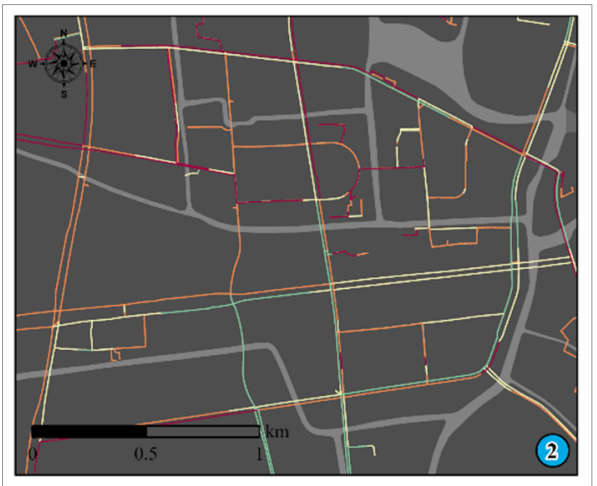

(c)

Figure 7. Distribution of cycling rhythm with a focus on paths. (a) overall cycling rhythm of paths in urban area; (b) bidirectional inconsistency in cycling rhythm in Gusu District; (c) bidirectional inconsistency in cycling rhythm in Wuzhong District.

Large-scale local regional cycling rhythm maps were selected and enlarged as shown in Figure $7 b$,c. Here, bidirectional inconsistency in cycling rhythm could be observed clearly by the color difference. We verified through field investigation that the bidirectional cycling rhythm tends to balance when a good cycling environment is present on both sides of the road. Cycling rhythms are often remarkably different when a bicycle lane is present on one side but not on the other. Under the condition that both sides of the road have the same quality of cycling environment, the inconsistency in cycling rhythm is often caused by the nature of urban functional areas and residents' travel purpose. For instance, the cycling rhythm is faster in the path leading to a working place, whereas the return ride may be slower on the other side of the same road. In short, the asymmetry in cycling rhythm on the path is manifested as a rhythm difference among paths and as bidirectional inconsistency.

\subsection{Cycling Rhythms Based on Heterogeneity of Space-Time Cubes}

The cycling rhythm heterogeneity of different regions at different times of the day is revealed by urban chronotopes from the perspective of spatiotemporal analysis. A non-dissected space-time cube is a chaosphere, and the details inside are not easy to see. 
Therefore, the analysis results obtained by the space-time hot spot detection model with public bicycle stations as the basic space object by different cross-sections are shown in Figure 8. The $\mathrm{X}-\mathrm{Y}$ axis represents the urban space, and the vertical axis $\mathrm{T}$ represents the time of day with $30 \mathrm{~min}$ as the basic time unit. Figure 8a shows the spatial and temporal rhythm variation characteristic map of Suzhou at $24 \mathrm{~h}$ a day, and Figure $8 \mathrm{~b}-\mathrm{d}$ is the north-south and east-west longitudinal sections. Figure 9 shows the statistical analysis results of the number of hot spot feature cubes, cold spot feature cubes, and random feature cubes at different times.

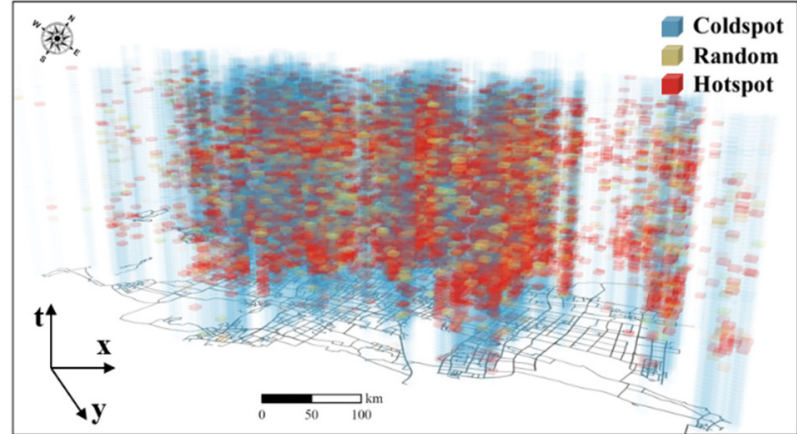

(a)

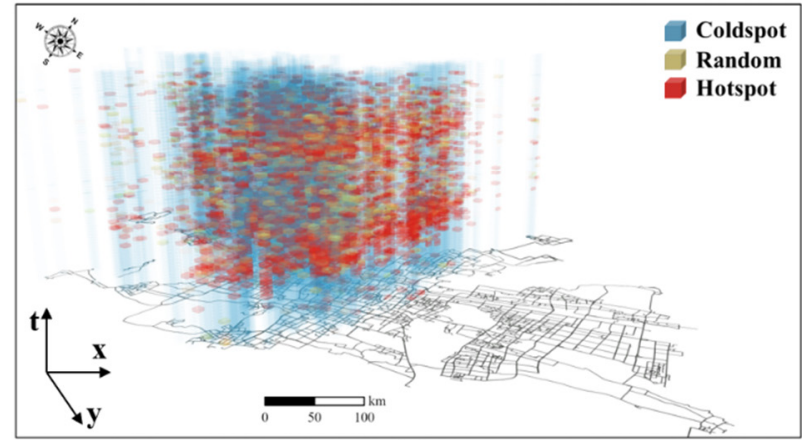

(c)

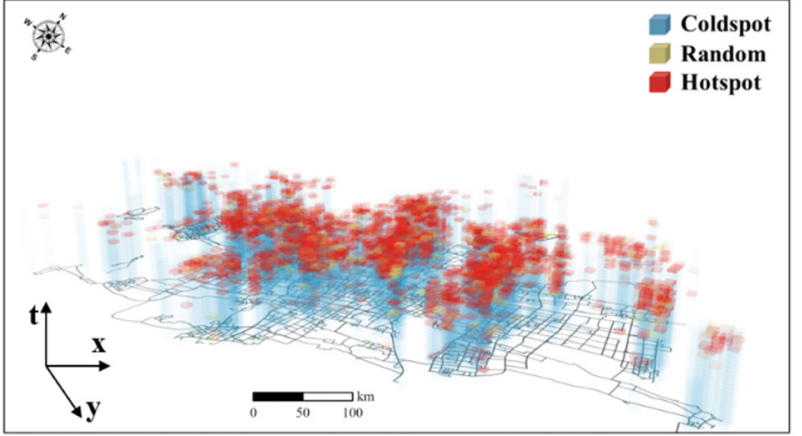

(b)

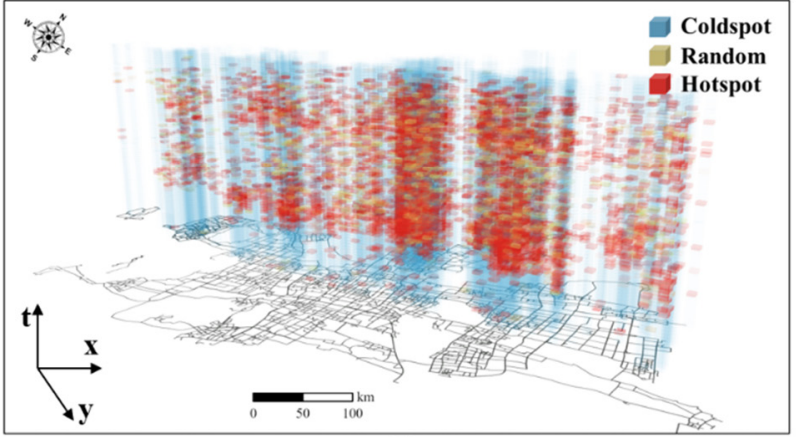

(d)

Figure 8. Space-time heterogeneity of cycling rhythm. (a) overall distribution; (b) time cross-section; (c) north-south longitudinal section; (d) east-west longitudinal section.

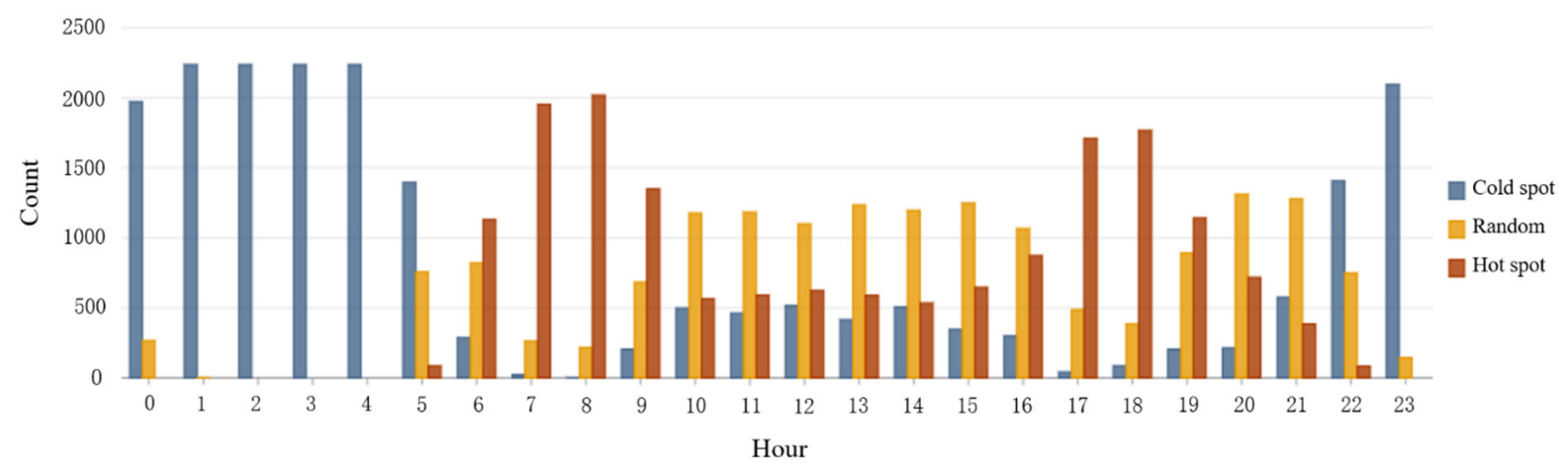

Figure 9. Statistical result of space-time cubes with cold-hot spot. 
The cycling rhythm in all urban regions is in complete cold spot mode between 2 a.m. and 4 a.m. and high-cold spot and low-random state between 11 p.m. and 1 a.m. Public bicycle rides in the city begin to recover at 5 a.m. The hot spots begin to rise in a high rhythm at 6 a.m. and reach the peak at 8 a.m. Another hot spot peak occurs from 4 p.m. to 7 p.m. The evening peak of the high rhythm is at 6 p.m. However, the rhythm degree of the evening peak is around $10 \%$ lower than that of the morning peak. In addition, a small night rush occurs between 7 p.m. and 8 p.m., in which the cycling rhythm is even higher than that in the afternoon. In general, spatiotemporal cubes with random features occur in the daytime, and the quantitative relationship of cubes with cold spots is exactly the opposite in time to that of cubes with hot spots. According to the profile visualization, the high rhythm with hot spots distribution gradually weakens from the urban area to the periphery in the shape of a small umbrella.

\subsection{Cycling Rhythms Focus on Spatiotemporal Patterns}

In this study, temporal multilayer characteristics of the cycling rhythm refer to the temporal rhythm patterns and ultrafine difference by special turning points. For the coarsergrained rhythm of variation, the spatiotemporal clustering method is able to provide a list of rhythmic patterns for a finer category. Four cycling rhythmic patterns with similar spatial and temporal rules were identified. As shown in Figure 10a, the distribution of these rhythmic patterns has remarkable overall spatial regularity. The cycling rhythm for Pattern 1 is located in the peripheral area of the city, especially in the west and north. In contrast, the cycling rhythm for Pattern 3 is concentrated on the west side of the city center, which belongs to the old city. The cycling rhythm for Pattern 4 is located in the east of the central city and shows a more remarkable agglomeration in distribution. Moreover, the cycling rhythm for Pattern 2 is widely distributed in the rural-urban continuum of the city and has small-range aggregation features.

More rhythm pattern differences could be observed from the characteristic curve of time change shown in Figure 10b. The time curve of Pattern 1 shows that its rhythm in a whole day is lower than the rhythms of the other three patterns in the same period. This result indicates that the cycling rhythm in suburban areas is obviously slower than that in the inner city. Interestingly, the rhythm change curve for Pattern 2 shows that its rhythm is higher during the morning peak but much slower during other time periods. This difference may be due to the rush in cycling for the morning shift in the rural-urban continuum and less rush in the afternoon. The cycling rhythm curve for Pattern 3 is the most typical such that the rhythm degree in the morning peak is parallel to that in the evening peak with a small peak of noon rhythm from 11:30 a.m. to 1 p.m. Most uniquely, the cycling rhythm for Pattern 4 is also always high in off-peak hours during the day ( 9 a.m. to 4 p.m.) and night (7 p.m. to 10 p.m.). Combined with place semantic discovery, industrial parks with a strong working density may result in a faster cycling rhythm.

Moreover, subtle differences are discernible between large and small rhythmic peaks and valleys. For instance, the occurrence time of the morning peak in the cycling rhythm curves is 7 a.m. for Patterns 2 and 4, 7:30 a.m. for Pattern 1, and 8 a.m. for Pattern 3. Besides, the results show small cycling rhythm peaks at 5:30 a.m. for Patten 3 and 6 a.m. for Pattern 2. Notably, the cycling rhythm curves at noon are in the small tri-modal mode. For example, the occurrence time of the peak in cycling rhythm curves at noon is 11 a.m., 1:30 p.m., and 3 p.m. for Pattern 2; 11:30 a.m., 1 p.m., and 2:30 p.m. for Pattern 3; and 11:30 a.m., 12:30 a.m., and 3 p.m. for Pattern 4. The exception is that Pattern 1 has subtle fluctuations in cycling rhythm curves at noon. Similarly, the occurrence time of evening peaks in the cycling rhythm curves is 5 p.m. for Patterns 1 and 3, 5:30 p.m. for Pattern 4, and 6 p.m. for Pattern 2. Finally, the cycling rhythm at night is also active to some extent at 8 p.m. for Patterns 1-3, whereas that for Pattern 4 is still high until 10 p.m. In short, the cycling rhythms of urban residents in different locations and periods could be reflected clearly by the spatial structure distribution and rhythm change curve. 


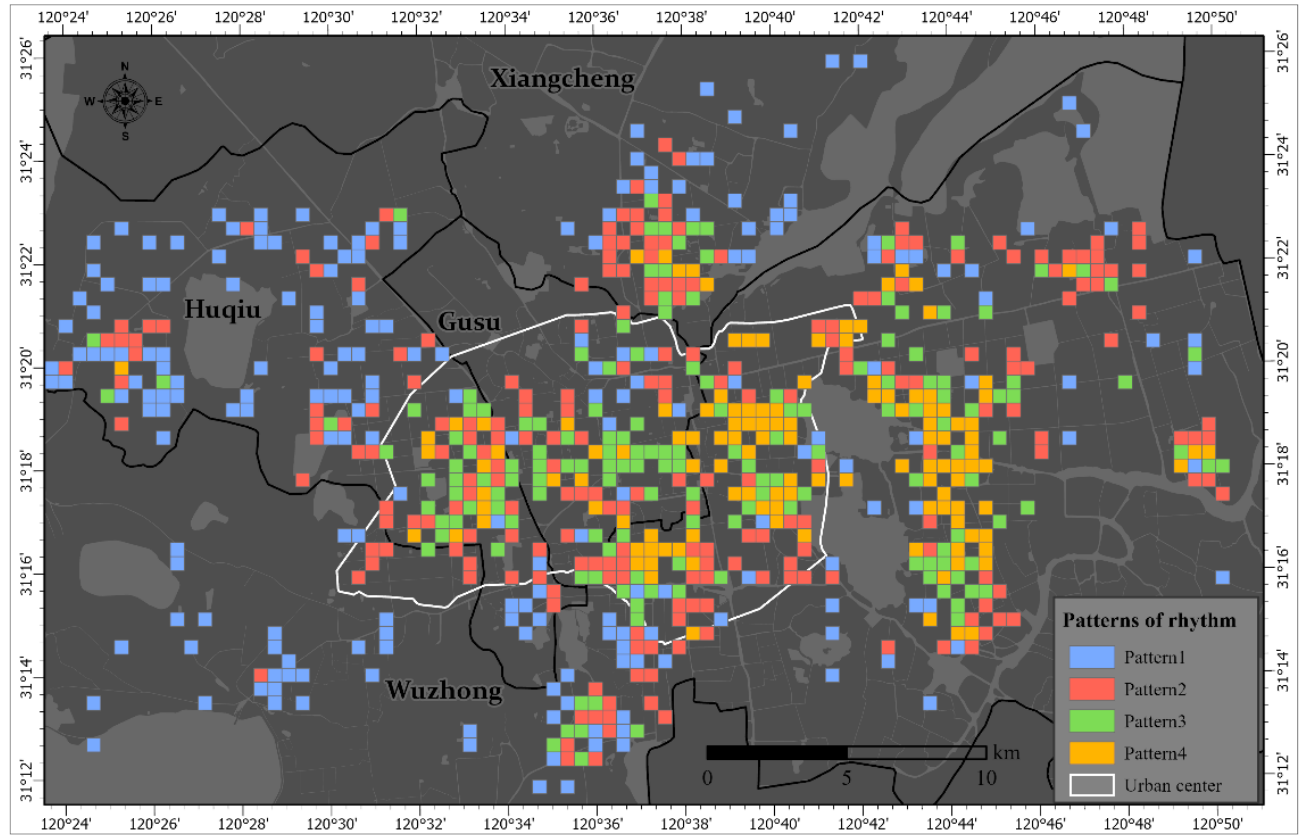

(a)

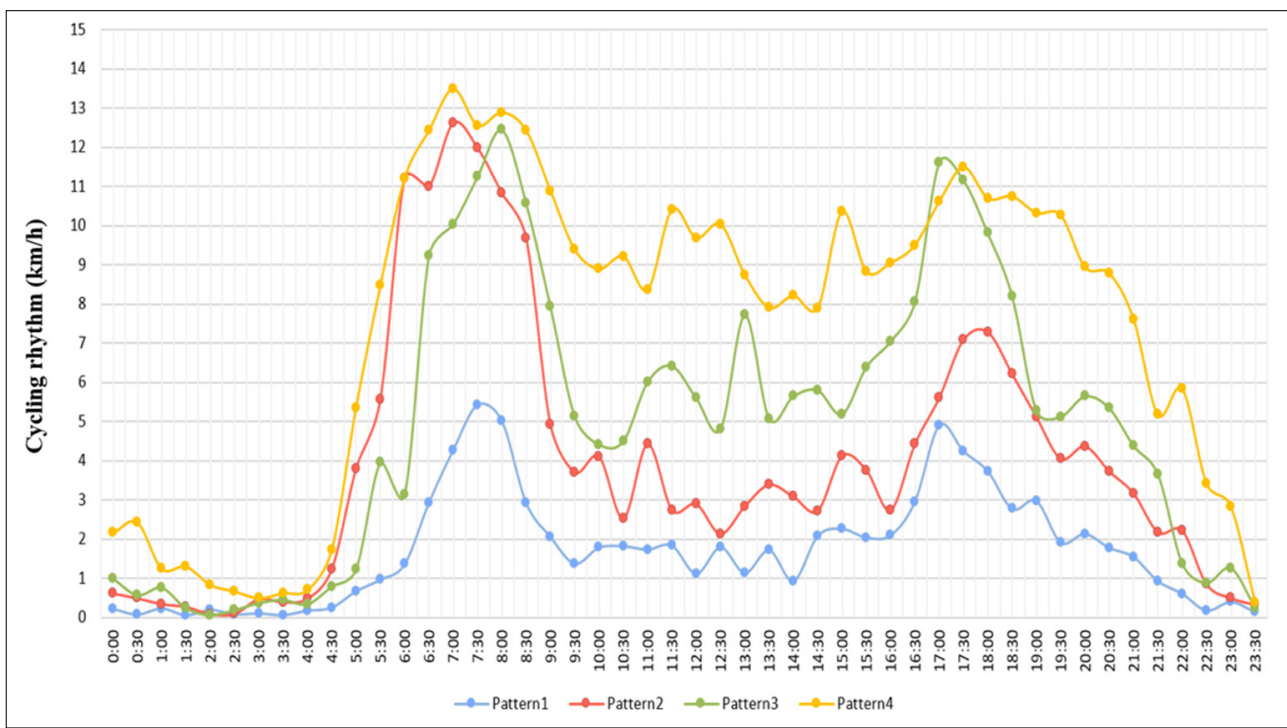

(b)

Figure 10. Spatiotemporal patterns of cycling rhythm. (a) distribution of cycling rhythm patterns in urban area; (b) ultrafine modes of cycling rhythms.

\section{Discussion}

\subsection{Selection of Representative Data for Rhythm Analysis}

The reliability of rhythm analysis is relevant to the steady state and peculiarity of the data. One of the questions worth discussing is how to screen out the specific homeostasis data of bicycle mobility rhythm from the continuous big database. In general, the variation in travel volume has specificity and periodicity, which change periodically on daily and weekly bases and remain relatively stable throughout the day or week. Simultaneously, public bicycles are more susceptible to weather factors because of outdoor exposure [48]. Congruent with the literature [49,50], out-of-range precipitation and temperature would lead to a decline in the number of public bicycle trips and the cyclists' experience of speed. Therefore, the calculation results of the cycling rhythm may be distorted by the 
amount of data and the instability of speeds. That is, the selection of cycling record data in an appropriate time period directly affects the universality and effectiveness of the cycling rhythm analysis results. In this study, the sub-datasets of sunny days, moderate temperature, and low wind speed were first selected from 1-year data according to daily weather, temperature, and wind speed. Then, through basic statistical analysis, the data of several days, in which the number of cycling records and average speed changes were relatively consistent, were further picked out. Finally, the data of a certain day on a workday instead of weekends were adopted to analyze the spatial and temporal rhythm characteristics to ensure the typicality and reasonability of the results of the cycling rhythm analysis to a certain extent.

\subsection{Causes of Cycling Rhythm Differences}

Our results have some differences when compared to a previous study conducted in Sweden (Eskilstuna, Linkoping, and Stockholm) based on data from speed and cycle flow data from 20 sites [51]. The results of this study show the average speed of cyclists on the paths varied between 12.5 and $26.5 \mathrm{~km} / \mathrm{h}$ using the equipment of MetroCount and an OTU3D camera system. However, these two studies are not completely comparable, because the bicycle types and cycling environment are different. Moreover, the difference of climatic conditions between Suzhou and Sweden is not comparable. Therefore, the cycling rhythm varies from city to city, although the differences in cycling speed are small.

According to rhythm characteristics with a focus on stations, paths, and spatiotemporal patterns, obvious rhythm differences in public bicycle use doubtlessly exist in urban chronotopes. The inconsistency in cycling rhythm even in different directions of the same section shows that public bicycle travel also has a certain tidal phenomenon. An exploration of the causes of the rhythmic differences revealed that the dominant factors regarding the road environment and travel behavior of cyclists might give rise to the phenomenon. For instance, cycling rhythm will be faster on roads with bicycle lanes and slower on roads without bicycle lanes. Thus, road segments with a low cycling rhythm could be field tested for the improvement or new construction of non-motorized lanes and bicycle lanes. In addition, the cycling rhythm will be slower when cycling upslope and faster when cycling downslope. Consequently, this result provides a train of thought for judging urban terrain. High bicycle flow will reduce the cycling rhythm, whereas free bicycle flow will develop a rhythm. The cycling rhythm for commuting is much higher than that for recreational activities. Cycling rhythm is also consciously higher when the purpose is fitness exercise. As reflected in the time dimension, cycling rhythm will be faster during morning and evening rush hours. Unexpectedly, the cycling rhythm will rise with a small spike from 8 p.m. to 10 p.m., which proves that public bicycles play a role in the urban night economy to some extent. Urban areas with special functions, such as industrial parks, which are dominated by high-tech companies and young workers, would bring some pressure or energy to the cycling rhythm.

\section{Conclusions}

This paper analyzed the characteristics of cycling rhythm from the aspects of public bicycle docking stations, cycling paths, and spatiotemporal variation. In summary, the rhythmic tapping of cycling is sparse and higher at night but much more intense and relatively lower in the daytime. From the perspective of stations, we found substantial inconsistencies in the cycling rhythm by a source-sink relationship comparison in terms of quantity and spatial distribution. High-cycling-rhythm areas have a binuclear cluster type with zonal distribution, and gradient changes in the acceleration and deceleration of cycling rhythm are relatively uniform in most areas. Besides, the asymmetry of the cycling rhythm on the paths is manifested as the rhythm difference among paths and as bidirectional inconsistency. From the perspective of spatiotemporal analysis, the high rhythm gradually weakens from the urban area to the periphery in the shape of a small umbrella. We also found four cycling rhythm patterns with different large and small 
rhythmic peaks and valleys. The cycling rhythm of the industrial park is faster because of the frequent contact between home and work. Lastly, night cycling by public bicycles is more active than expected.

Moreover, this paper demonstrates that full sample data of public bicycle trips allow scholars to explore the cycling rhythm by mobility perception to shed more light on the forces underpinning urban spatiotemporal structure. It unraveled remarkable inconsistency in the cycling rhythm among stations and the asymmetry of paths. Temporal multilayer and spatial mismatch in cycling rhythms were found, which suggests that the cycling environment and occupation-residential function should be considered in active transport demand management and urban planning. Finally, it identified the inflection points of cycling rhythms where the travel behavioral preference changes, as well as the exact road segments with slow rhythms. This finding is useful in the layout design of public bicycle stations. Transport planners should improve bicycle lane construction where cyclists suffer from a slow cycling rhythm. For example, a well-signed and flat cycling corridor could be introduced between workplaces and residences with many regular commuters. In addition, cities can prosper by constructing bicycle lanes for nightlife districts. As the public bicycle system is widely used in many cities all over the world, the rhythm analysis of public bicycle systems is of specific universality. The life rhythm in different cities can be found and distinguished, thereby putting forward the corresponding countermeasures for urban planning and transport design.

Still, several limitations need to be mentioned. One limitation is that we focused on the study of full sample data of one-day's public bicycle trips, which reflects the cycling rhythm of the early summer regular weather in a workday. We did not observe other cycling rhythms in other situations (e.g., weekends, winter, rainy days) and detailed cycling processes (e.g., waiting for red lights, looking for directions, shopping on the way). Although we have tried to improve the accuracy of cycling path estimation by the choice of an online map with good quality, strict screening outliers, and small sample verification of personal experience by researchers, there may still be path matching deviation. This error might cause some fluctuation in path distance determination and corresponding rhythm value calculations. However, this problem may need to be solved by improved tracking devices for public bicycles in the future. We may capture cycling rhythm rules for weeks and months for public bicycle mobility using various datasets in a longer time dimension. We may be able to provide more specific cycling rhythm profiles for seasonal comparison and corresponding influencing factors using more weather data. In addition, the cycling rhythm will be different if private bicycles are taken into account. This is another interesting topic worth investigating further in the future.

Author Contributions: Conceptualization, Lijun Chen; methodology, Lijun Chen and Shangjing Jiang; visualization, Shangjing Jiang; validation, Lijun Chen; investigation, Lijun Chen; resources, Lijun Chen; writing-original draft preparation, Lijun Chen; writing-review and editing, Lijun Chen; project administration, Lijun Chen. All authors have read and agreed to the published version of the manuscript.

Funding: This research is supported by the National Natural Science Foundation of China (51408386).

Institutional Review Board Statement: Not applicable.

Informed Consent Statement: Not applicable.

Data Availability Statement: Due to confidentiality agreements, supporting data can only be made available to bona fide researchers subject to a non-disclosure agreement.

Acknowledgments: Special thanks Urban Management Bureau of Suzhou Municipality for data support.

Conflicts of Interest: The authors declare no conflict of interest. 


\section{References}

1. Li, C.; Xiao, W.; Zhang, D.; Ji, Q. Low-carbon transformation of cities: Understanding the demand for dockless bike sharing in China. Energy Policy 2021, 159, 112631. [CrossRef]

2. Nielsen, T.A.S.; Skov-Petersen, H. Bikeability-Urban structures supporting cycling. Effects of local, Urban and regional scale urban form factors on cycling from home and workplace locations in Denmark. J. Transp. Geogr. 2018, 69, 36-44. [CrossRef]

3. Osman, R.; Mulíček, O. Urban chronopolis: Ensemble of rhythmized dislocated places. Geoforum 2017, 85, 46-57. [CrossRef]

4. Hesse, M. Cities and flows: Re-asserting a relationship as fundamental as it is delicate. J. Transp. Geogr. 2013, 29, 33-42. [CrossRef]

5. Watanabe, H.; Chikaraishi, M.; Maruyama, T. How different are daily fluctuations and weekly rhythms in time-use behavior across urban settings? A case in two Japanese cities. Travel Behav. Soc. 2021, 22, 146-154. [CrossRef]

6. Gao, J.; Kamphuis, C.B.M.; Helbich, M.; Ettema, D. What is 'neighborhood walkability'? How the built environment differently correlates with walking for different purposes and with walking on weekdays and weekends. J. Transp. Geogr. 2020, 88, 102860. [CrossRef]

7. Hall, C.M.; Ram, Y. Walk score and its potential contribution to the study of active transport and walkability: A critical and systematic review. Transp. Res. Part D Transp. Environ. 2018, 61, 310-324. [CrossRef]

8. Golakiyaa, H.D.; Ritvik Chauhanb, A.D. Mapping Pedestrian-Vehicle Behavior at Urban Undesignated Mid-Block Crossings under Mixed Traffic Environment-A Trajectory-Based Approach. Transp. Res. Procedia 2020, 48, 1263-1277. [CrossRef]

9. Clarry, A.; Faghih Imani, A.; Miller, E.J. Where we ride faster? Examining cycling speed using smartphone GPS data. Sustain. Cities Soc. 2019, 49, 101594. [CrossRef]

10. Dictionary, C. Conception of Rhythm. Available online: https://baike.baidu.com/item/\%E8\%8A\%82\%E5\%A5\%8F/3795?fr= aladdin (accessed on 25 December 2013).

11. Lefebvre, H. The Production of Space; Blackwell Publishers: Oxford, UK, 1991.

12. Lefebvre, H. Rhythmanalysis: Space, Time and Everyday Life; Continium: London, UK, 2004.

13. Antchak, V. City rhythms and events. Ann. Tour. Res. 2018, 68, 52-54. [CrossRef]

14. Volo, S. Urban rhythms and travel behaviour: Spatial and temporal phenomena of daily travel. Ann. Tour. Res. 2011, 38, 723-725. [CrossRef]

15. Schleinitz, K.; Petzoldt, T.; Gehlert, T. Risk compensation? The relationship between helmet use and cycling speed under naturalistic conditions. J. Saf. Res. 2018, 67, 165-171. [CrossRef]

16. Dominoni, D.M.; Helm, B.; Lehmann, M.; Dowse, H.B.; Partecke, J. Clocks for the city: Circadian differences between forest and city songbirds. Proc. R. Soc. B-Biol. Sci. 2013, 280, 20130593. [CrossRef] [PubMed]

17. Tran, H.A.; Yip, N.-M. Rhythm of endurance and contestation: Everyday practices of roaming vendors in Hanoi. Geoforum 2020, 117, 259-267. [CrossRef]

18. Mulíček, O.; Osman, R. Rhythm of urban retail landscapes: Shopping hours and the urban chronotopes. Morav. Geogr. Rep. 2018, 26, 2-13. [CrossRef]

19. Wey, D.; Bohn, A.; Menna-Barreto, L. Daily rhythms of native Brazilians in summer and winter. Physiol. Behav. 2012, 105, 613-620. [CrossRef]

20. Johansen, P.H.; Fisker, J.K.; Thuesen, A.A. 'We live in nature all the time': Spatial justice, outdoor recreation, and the refrains of rural rhythm. Geoforum 2021, 120, 132-141. [CrossRef]

21. Flemsæter, F.; Stokowski, P.; Frisvoll, S. The rhythms of canal tourism: Synchronizing the host-visitor interface. J. Rural Stud. 2020, 78, 199-210. [CrossRef]

22. Rantala, O.; Valtonen, A. A rhythmanalysis of touristic sleep in nature. Ann. Tour. Res. 2014, 47, 18-30. [CrossRef]

23. Ambühl, L.; Loder, A.; Leclercq, L.; Menendez, M. Disentangling the city traffic rhythms: A longitudinal analysis of MFD patterns over a year. Transp. Res. Part C Emerg. Technol. 2021, 126, 103065. [CrossRef]

24. Csáji, B.C.; Browet, A.; Traag, V.A.; Delvenne, J.-C.; Huens, E.; Van Dooren, P.; Blondel, V.D. Exploring the mobility of mobile phone users. Phys. A Stat. Mech. Its Appl. 2013, 392, 1459-1473. [CrossRef]

25. Ahas, R.; Aasa, A.; Silm, S.; Tiru, M. Daily rhythms of suburban commuters' movements in the Tallinn metropolitan area: Case study with mobile positioning data. Transp. Res. Part C Emerg. Technol. 2010, 18, 45-54. [CrossRef]

26. Ma, T.; Pei, T.; Song, C.; Liu, Y.; Du, Y.; Liao, X. Understanding geographical patterns of a city's diurnal rhythm from aggregate data of location-aware services. Trans. GIS 2018, 23, 104-117. [CrossRef]

27. Liu, K.; Murayama, Y.; Ichinose, T. A multi-view of the daily urban rhythms of human mobility in the Tokyo metropolitan area. J. Transp. Geogr. 2021, 91, 102985. [CrossRef]

28. Barbour, N.; Zhang, Y.; Mannering, F. A statistical analysis of bike sharing usage and its potential as an auto-trip substitute. J. Transp. Health 2019, 12, 253-262. [CrossRef]

29. Böcker, L.; Anderson, E.; Uteng, T.P.; Throndsen, T. Bike sharing use in conjunction to public transport: Exploring spatiotemporal, age and gender dimensions in Oslo, Norway. Transp. Res. Part A Policy Pract. 2020, 138, 389-401. [CrossRef]

30. Qian, X.; Jaller, M. Bikesharing, equity, and disadvantaged communities: A case study in Chicago. Transp. Res. Part A Policy Pract. 2020, 140, 354-371. [CrossRef]

31. Wang, J.; Lindsey, G. Neighborhood socio-demographic characteristics and bike share member patterns of use. J. Transp. Geogr. 2019, 79, 102475. [CrossRef] 
32. Fishman, E.; Washington, S.; Haworth, N.; Mazzei, A. Barriers to bikesharing: An analysis from Melbourne and Brisbane. J. Transp. Geogr. 2014, 41, 325-337. [CrossRef]

33. Orvin, M.M.; Fatmi, M.R. Why individuals choose dockless bike sharing services? Travel Behav. Soc. 2021, 22, 199-206. [CrossRef]

34. Ayachi, F.S.; Dorey, J.; Guastavino, C. Identifying factors of bicycle comfort: An online survey with enthusiast cyclists. Appl. Ergon. 2015, 46 Pt A, 124-136. [CrossRef]

35. Dozza, M.; Werneke, J. Introducing naturalistic cycling data: What factors influence bicyclists' safety in the real world? Transp. Res. Part F Traffic Psychol. Behav. 2014, 24, 83-91. [CrossRef]

36. Fyhri, A.; Sundfør, H.B.; Weber, C.; Phillips, R.O. Risk compensation theory and bicycle helmets-Results from an experiment of cycling speed and short-term effects of habituation. Transp. Res. Part F Traffic Psychol. Behav. 2018, 58, 329-338. [CrossRef]

37. Boufous, S.; Hatfield, J.; Grzebieta, R. The impact of environmental factors on cycling speed on shared paths. Accid. Anal. Prev. 2018, 110, 171-176. [CrossRef]

38. Schleinitz, K.; Petzoldt, T.; Franke-Bartholdt, L.; Krems, J.; Gehlert, T. The German Naturalistic Cycling Study-Comparing cycling speed of riders of different e-bikes and conventional bicycles. Saf. Sci. 2017, 92, 290-297. [CrossRef]

39. Schleinitz, K.; Petzoldt, T.; Krems, J.F.; Gehlert, T. The influence of speed, cyclists' age, pedaling frequency, and observer age on observers' time to arrival judgments of approaching bicycles and e-bikes. Accid. Anal. Prev. 2016, 92, 113-121. [CrossRef]

40. Petzoldt, T.; Schleinitz, K.; Krems, J.F.; Gehlert, T. Drivers' gap acceptance in front of approaching bicycles-Effects of bicycle speed and bicycle type. Saf. Sci. 2017, 92, 283-289. [CrossRef]

41. Bendik Manum, P.A.T.N.; Jorge, G. Improving GIS-based models for bicycling speed estimations. Transp. Res. Procedia 2018, 42, 85-99. [CrossRef]

42. Khan, S.I.; Singh, B. Interval distribution for exclusive, mixed-use bicycle paths. Transp. Res. Rec. 2001, 1776, 229-236. [CrossRef]

43. Joo, S.; Oh, C.; Jeong, E.; Lee, G. Categorizing bicycling environments using GPS-based public bicycle speed data. Transp. Res. Part C Emerg. Technol. 2015, 56, 239-250. [CrossRef]

44. Jensen, P.; Rouquier, J.-B.; Ovtracht, N.; Robardet, C. Characterizing the speed and paths of shared bicycle use in Lyon. Transp. Res. Part D Transp. Environ. 2010, 15, 522-524. [CrossRef]

45. Naimi, B.; Hamm, N.A.S.; Groen, T.A.; Skidmore, A.K.; Toxopeus, A.G.; Alibakhshi, S. ELSA: Entropy-based local indicator of spatial association. Spat. Stat. 2019, 29, 66-88. [CrossRef]

46. Montero, P.; Vilar, J.A. Tsclust: An R Package for Time Series Clustering. J. Stat. Softw. 2014, 62, 1-43. [CrossRef]

47. Yan, X.; Feng, Y.; Tong, X.; Li, P.; Zhou, Y.; Wu, P.; Wang, C. Reducing spatial autocorrelation in the dynamic simulation of urban growth using eigenvector spatial filtering. Int. J. Appl. Earth Obs. Geoinf. 2021, 102, 102434. [CrossRef]

48. Chen, L.J.; Pel, A.J.; Chen, X.; Sparing, D.; Hansen, I.A. Determinants of Bicycle Transfer Demand at Metro Stations: Analysis of Stations in Nanjing, China. Transp. Res. Rec. 2012, 2276, 131-137. [CrossRef]

49. Chen, L.; Zhang, H.; Wang, H.; Wu, P. Understanding Plum Rain's Effects on Urban Public Bicycle Unavailability Considering Both Place Semantics and Riding Distance. ISPRS Int. J. Geo-Inf. 2021, 10, 695. [CrossRef]

50. Liu, C.; Susilo, Y.O.; Karlström, A. The influence of weather characteristics variability on individual's travel mode choice in different seasons and regions in Sweden. Transp. Policy 2015, 41, 147-158. [CrossRef]

51. Eriksson, J.; Forsman, A.; Niska, A.; Gustafsson, S.; Sorensen, G. An analysis of cyclists' speed at combined pedestrian and cycle paths. Traffic Inj. Prev. 2019, 20, 56-61. [CrossRef] 